\title{
PERSEBARAN KOMODITI JERUK MANIS KECAMATAN PASAMAN KABUPATEN PASAMAN BARAT
}

\author{
Supandri ${ }^{1}$, Febriandi ${ }^{2}$ \\ Program Studi Geografi \\ Fakultas Ilmu Sosial
}

\begin{abstract}
ABSTRAK
Penelitian ini bertujuan untuk membahas tentang persebaran komoditi jeruk manis di Kecamatan Pasaman kabupaten Pasaman Barat. Metode yang di pakai metode deskriptif dengan pendekatan kuantitatif. Variabel dalam penelitian ini adalah tingkat produktivitas,pmasaran dan penyebaran jeruk manis. Penentuan sampel dalam penelitian ini dilakukan dengan menggunakan metode acak sederhana (simple random sampling). Teknik pengumpulan data yang digunakan adalah teknik angket. Hasil penelitian didapatkan melalui wawancara angket serta melakukan penelitian di lapangan di Kecamatan Pasaman Kabupaten Pasaman Barat.
\end{abstract}

Kata Kunci : persebaran, pemasaran dan tingkt produktivitas jeruk manis

\begin{abstract}
This research aims to discuss about the distribution of sweet orange commodities in Pasaman sub-district Barat District. Methods are used in a descriptive method with a quantitative approach. The variables in this study are the level of productivity, the Marketing and spread of sweet oranges. The sample determination in the study was done using simple random methods (simple random sampling). The data collection techniques used are poll techniques. The research results are obtained through poll interviews as well as conducting research on the field in Pasaman sub-district of Pasaman Barat. The results of this research in the pattern of sweet citrus plants in Pasaman subdistrict is spread evenly (Scattered), The sweet orange productivity level is 29.51 tons/th and the marketing is $11.11 \%$ Direct marketing and 88.88 indirect.
\end{abstract}

Keyword : Distribution, marketing, and high-orange productivity

${ }^{1}$ Mahasiswa Geografi Universitas Negeri Padang

${ }^{2}$ Dosen Geografi Universitas Negeri Padang 


\section{PENDAHULUAN}

Latar Belakang

Sektor perkebunan merupakan sektor yang memegang peran penting dalam program pembangunan khusus di sektor pertanian, sektor pertanian menjadi tempat bagi petani untuk menggantungkan hidupnya sebagai cabang usaha yang berfungsi menciptakan lapangan kerja.

Hasil pertanian diharapkan dapat meningkatkan kesejahteraan dan kemakmuran rakyat terutama masyarakat petani, negara kita dikenal sebagai negara agraris dan potensi sumber daya lahannya mendukung, karena itu diharapkan petani mampu meningkatkan hasil pertaniannya untuk memenuhi kebutuhan hidup sehari-hari dan meningkatkan devisa negara dengan cara ekspor serta memperluas kesempatan kerja.

Kecamatan Pasaman merupakan salah satu Kabupaten Pasaman Barat di Sumatera Barat yang memiliki luas perkebunan jeruk rakyat seluas 4,896 Ha (BPS 2017). Nagari-nagari di Kecamatan Pasaman sudah banyak dikembangkan budidaya tanaman jeruk manis, salah satunya adalah Kenagarian Aia Gadang, Aua Kuning dan Lingkuang Aua.

\begin{tabular}{ccc} 
No & $\begin{array}{c}\text { Nama } \\
\text { Nagari }\end{array}$ & $\begin{array}{c}\text { Jumlah } \\
\text { Penduduk }\end{array}$ \\
\hline 1 & Aua kuning & 22.282 \\
\hline 2 & Aia Gadang & 13.637 \\
\hline 3 & $\begin{array}{l}\text { Lingkuang } \\
\text { Aua }\end{array}$ & 39.242 \\
& Jumlah & $\mathbf{7 5 . 1 6 1}$
\end{tabular}

Tabel I.I: Nagari di Kecamatan Pasaman BPS,2017

\section{KAJIAN TEORI}

Jeruk (Citrussp) merupakan salah satu komoditi buah-buahan yang mempunyai peranan penting di pasaran dunia maupun dalam negeri, baik dalam bentuk segar maupun olahannya. Karena mempunyai nilai ekonomi tinggi maka pemerintah mengarahkan pengelolaan jeruk manis bagi petani kecil untuk dikembangkan, Jeruk manis mempunyai rasa yang manis dan kandungan air yang banyak serta kandungan vitamin $\mathrm{C}$ yang tinggi (berkisar 27-49 mg/100 gram daging buah). Vitamin $\mathrm{C}$ bermanfaat sebagai antioksi dan dalam tubuh yang dapat mencegah kerusakan sel akibat aktivitas molekul radikal bebas (Kusuma retno dkk,2013)..

Kabupaten Pasaman Barat Kecamatan Pasaman sebagai sentra agrobisnis pengembangan budidaya jeruk manis kedepannya yakni salah satunya adalah Nagari Lingkuang Aua, Aia Gadang dan Aua Kuniang di Kecamatan Pasaman. untuk lebih jelas nya dapat dilihat pada tabel di

\section{3, METODOLOGI PENELITAN}

\section{A. Jenis Penelitian}

Metode kombinasi adalah merupakan pendekatan penelitian yang menggabungkan atau menghubungkan metode penelitian kuantitatif dan kualitatif.

Penelitian kombinasi adalah merupakan penelitian, dimana peneliti mengumpulkan data, dan 
mengintegrasikan temuan, secara inferensial dengan menggunakan dua pendekatan atau metode penelitian kualitatif dan kuantitatif dalam satu studi.Metode kombinasi digunakan untuk menjawab pertanyaan penelitian pada satu penelitian.

\section{B. Populasi dan Sampel}

\section{Populasi Penelitian}

Populasi adalah keseluruhan subyek yang akan diteliti (SulistyoBasuki,2006).

\section{2, Sampel Penelitian}

Sampel adalah bagian tertentu dari keseluruhan subyek yang akan diteliti (SulistyoBasuki,2006). Berdasarkan populasi penelitian yang telah di tetapkan, maka sampel penelitian diambil dengan teknik "Proporsional Random Sampling" dengan proporsi $20 \%$ dari populasi penelitian.

Menurut Arikunto (2006) sampel penelitian yang populasi kurang dari $100 \%$ lebih baik diambil semuanya, akan tetapi apabila lebih dari dari 100 maka jumlah sampel diambil antara 15-20 $\%$ atau lebih.

Kecamatan Pasaman, terdiri dari tiga Nagari yang penduduknya berpropensi sebagai petani jeruk manis 225 sampel yang diambil $20 \%$ dari jumlah populasi yaitu sebanyak $45 \mathrm{KK}$, untuk lebih jelasnya dapat dilihat pada tabel berikut ini:

\section{N o. Jenis Jumlah Pekerjaan}

\begin{tabular}{clc}
\hline 1 & Pegawai & 13.424 \\
\hline 2 & Petani & 30.672 \\
\hline 3 & Jasa & 20.675 \\
\hline & Jumlah & $\mathbf{6 9 . 7 7 1}$
\end{tabular}

Tabel III.1 Jumlah penduduk berdasarkan mata pencaharian BPS 2014

Teknik pengambilan sampel pada penelitian ini yaitu menggunakan cara Proporsional Random Sampling biasa digunakan pada populasi yang mempunyai susunan bertingkat atau berlapislapis. Teknik ini digunakan bila populasi mempunyai anggota/unsur yang tidak homogen dan berstrata secara proporsional. Maka sampel penelitian ini adalah masyarakat yang bekerja sebagai petani jeruk untuk lebih jelasnya dapat dilihat pada tabel di bawah ini sebagai berikut:

\begin{tabular}{llcc} 
No & Nagari & $\begin{array}{c}\text { Petani } \\
\text { Jeruk } \\
\text { Manis } \\
\text { (KK) }\end{array}$ & $\begin{array}{c}\text { Juml } \\
\text { ah } \\
\text { Samp } \\
\text { el } \\
(\mathbf{2 0 \%} \\
\text { ) }\end{array}$ \\
\hline 1 & $\begin{array}{l}\text { Aua } \\
\text { kuning }\end{array}$ & 45 & 9 \\
\hline 2 & $\begin{array}{l}\text { Ligkua } \\
\text { ng aua }\end{array}$ & 76 & 16 \\
\hline 3 & $\begin{array}{l}\text { Aia } \\
\text { gadang }\end{array}$ & 104 & 20 \\
\hline & Jumlah & $\mathbf{2 2 5}$ & $\mathbf{4 5}$
\end{tabular}


Tabel III.2 Sampel penelitian petani jeruk manis BPS 2017

Metode analisa yang dipakai dalam penelitian kulitatif melalui beberapa tahapan analisa data yaitu:

\section{Hasil Penelitian}

Luas daerah di Kecamatan Pasaman terdiri dari 3 nagari yaitu: Aie Gadang, Aur Kuning dan Lingkuang Aua. Nagari yang terluas yaitu Koto Tinggi sebesar $74,00 \mathrm{~km}^{2}$ dan yang terkecil Nagari Talang Anau sebesar 18,54 km².

1. Persebaran Lahan jeruk manis di Kecamatan Pasaman Kabupaten Pasaman Barat.

Berdasarkan data yang diperoleh di lapangan persebaran lahan Jeruk Manis di Kecamatan Pasaman tersebar secara merata di Kecamatan Pasaman terdapat 45 lahan jeruk manis yang tersebar di Nagari Aia Gadang, Aur Kuning, Kelurahan dan Nagari Lingkuang Aua, Penelitian ini menggunakan Software Arcgis 10.1. Sedangkan untuk mengetahui pola persebaran nya menggunakan teknik presentase

Berdasarkan penelitian yang telah dilakukan, ditemukan 45 titik sampel Lahan Jeruk Manis, titik titik tersebut dapat di tabelkan sebagai berikut.

\begin{tabular}{lcrr}
\hline N & TITIK & \multicolumn{2}{c}{ KOORDINAT } \\
\cline { 2 - 3 } O & SAMPEL & \multicolumn{1}{c}{$\mathbf{X}$} & \multicolumn{1}{c}{$\mathbf{Y}$} \\
\hline \hline & & 99.711496 & 0.150286 \\
1 Sampel 1 & 04450 & 15385 \\
\hline
\end{tabular}

\begin{tabular}{|c|c|c|}
\hline \multirow[b]{2}{*}{2 Sampel 2} & 99.730940 & 0.137664 \\
\hline & 43680 & 35536 \\
\hline \multirow[b]{2}{*}{3 Sampel 3} & 99.764030 & 0.160520 \\
\hline & 01660 & 04452 \\
\hline \multirow{3}{*}{4 Sampel 4} & 99.763688 & 0.129477 \\
\hline & 88690 & 24282 \\
\hline & 99.790979 & 0.158132 \\
\hline \multirow[t]{2}{*}{5 Sampel 5} & 26200 & 13669 \\
\hline & 99.830550 & 0.171095 \\
\hline \multirow[t]{2}{*}{6 Sampel 6} & 30590 & 06487 \\
\hline & 99.845218 & 0.189174 \\
\hline \multirow[t]{2}{*}{7 Sampel 7} & 88260 & 93839 \\
\hline & 99.833961 & 0.154720 \\
\hline \multirow[t]{2}{*}{8 Sampel 8} & 60280 & 83980 \\
\hline & 99.753454 & 0.151650 \\
\hline \multirow[t]{2}{*}{9 Sampel 9} & 99620 & 67260 \\
\hline & 99.848289 & 0.149262 \\
\hline \multirow[t]{2}{*}{ 10Sampel 10} & 04980 & 76478 \\
\hline & 99.867733 & 0.181670 \\
\hline \multirow[t]{2}{*}{ 11 Sampel 11} & 44200 & 08523 \\
\hline & 99.722753 & 0.120266 \\
\hline \multirow[t]{2}{*}{ 12 Sampel 12} & 32420 & 74122 \\
\hline & 99.697850 & 0.115832 \\
\hline \multirow[t]{2}{*}{ 13 Sampel 13} & 85690 & 05526 \\
\hline & 99.674312 & 0.096046 \\
\hline \multirow[t]{2}{*}{ 14Sampel 14} & 90840 & 53330 \\
\hline & 99.703650 & 0.084789 \\
\hline \multirow[t]{2}{*}{ 15 Sampel 15} & 06170 & 25357 \\
\hline & 99.757207 & 0.091611 \\
\hline \multirow[t]{2}{*}{ 16Sampel 16} & 42280 & 84735 \\
\hline & 99.755842 & 0.108668 \\
\hline \multirow[t]{2}{*}{ 17Sampel 17} & 90410 & 33180 \\
\hline & 99.786885 & 0.089565 \\
\hline \multirow[t]{2}{*}{ 18 Sampel 18} & 70580 & 06921 \\
\hline & 99.818269 & 0.098093 \\
\hline \multirow[t]{2}{*}{ 19Sampel 19} & 63710 & 31144 \\
\hline & 99.788591 & 0.077284 \\
\hline 20Sampel 20 & 35420 & 40041 \\
\hline
\end{tabular}




\begin{tabular}{|c|c|c|}
\hline \multirow[b]{2}{*}{21 Sampel 21} & 99.809059 & 0.068073 \\
\hline & 13550 & 89881 \\
\hline & 99.746291 & 0.081719 \\
\hline \multirow[t]{2}{*}{ 22 Sampel 22} & 27280 & 08637 \\
\hline & 99.882743 & 0.165978 \\
\hline \multirow[t]{2}{*}{ 23 Sampel 23} & 14840 & 11954 \\
\hline & 99.867733 & 0.146874 \\
\hline \multirow[t]{2}{*}{ 24 Sampel 24} & 44200 & 85696 \\
\hline & 99.867051 & 0.095364 \\
\hline \multirow[t]{2}{*}{25 Sampel 25} & 18270 & 27393 \\
\hline & 99.855452 & 0.096728 \\
\hline \multirow[t]{2}{*}{ 26Sampel 26} & 77320 & 79268 \\
\hline & 99.877626 & 0.106621 \\
\hline \multirow[t]{2}{*}{ 27Sampel 27} & 20300 & 55366 \\
\hline & 99.907986 & 0.083083 \\
\hline \multirow[t]{2}{*}{ 28Sampel 28} & 74530 & 60512 \\
\hline & 99.958815 & 0.098093 \\
\hline \multirow[t]{2}{*}{ 29Sampel 29} & 06900 & 31144 \\
\hline & 99.916856 & 0.125383 \\
\hline \multirow[t]{2}{*}{ 30 Sampel 30} & 11730 & 68655 \\
\hline & 99.841125 & 0.087177 \\
\hline \multirow[t]{2}{*}{31 Sampel 31} & 32630 & 16139 \\
\hline & 99.836349 & 0.165636 \\
\hline \multirow[t]{2}{*}{ 32 Sampel 32} & 51070 & 98985 \\
\hline & "99.783133 & 0.163931 \\
\hline \multirow[t]{2}{*}{ 33 Sampel 33} & 27920 & 34140 \\
\hline & 99.754819 & 0.130500 \\
\hline \multirow[t]{2}{*}{ 34 Sampel 34} & 51500 & 63189 \\
\hline & 99.744244 & 0.116855 \\
\hline \multirow[t]{2}{*}{ 35 Sampel 35} & 49460 & 44433 \\
\hline & 99.696145 & 0.100822 \\
\hline \multirow[t]{2}{*}{ 36 Sampel 36} & 20850 & 34895 \\
\hline & 99.661349 & 0.109691 \\
\hline \multirow[t]{2}{*}{37 Sampel 37} & 98020 & 72086 \\
\hline & 99.910715 & 0.060569 \\
\hline \multirow[t]{2}{*}{38 Sampel 38} & 78290 & 04565 \\
\hline & 99.937323 & 0.062956 \\
\hline 39Sampel 39 & 89860 & 95348 \\
\hline
\end{tabular}

\begin{tabular}{lrr}
\hline & 99.925043 & 0.108327 \\
40Sampel 40 & 22980 & 20211 \\
\hline \hline & 99.819975 & 0.145851 \\
41 Sampel 41 & 28560 & 46789 \\
\hline \hline & 99.767782 & 0.138687 \\
42 Sampel 42 & 44320 & 74442 \\
\hline \hline & 99.809355 & 0.120715 \\
43 Sampel 43 & 99220 & 22614 \\
\hline \hline & 99.778698 & 0.094340 \\
44Sampel 44 & 59320 & 88486 \\
\hline \hline & 99.757889 & 0.116514 \\
45 Sampel 45 & 68220 & 31464 \\
\hline Tabel IV I Sampel penelitian di
\end{tabular}

Tabel IV .I Sampel penelitian di Kecamatan Pasaman, Data Primer 2019.

\section{Tingkat Produktivitas Jeruk Manis di Kecamatan Pasaman}

Dari hasil penelitian maka di dapatkan tingkt produktifitas jeruk manis dalam waktu satu tahun sebagai berikut: lahan jeruk manis di Kecamatan Pasaman Kabupaten Pasaman Barat memiliki pola persebaran nya yang mengelompok sehingga tingkat produktifitas jeruk manis di Kecamatan Pasaman rendah.

Dari hasil peneliti di lapangan tingkat produktifitas jeruk manis di Kecamatan Pasaman Kabupaten Pasaman Barat memiliki lahan yang kekurangan akibat terjepit nya oleh lahan kelapa sawit yang mengakibatkan hasil panen jeruk manis rendah, disamping itu jalan juga mempunyai fungsi untuk memperlancar kegiatan ekonomi. 
Produktivitas

$=\frac{\text { Jumlah produksi (ton) }}{\text { Luas lahan }(\mathrm{Ha})}$

Produktivitas $=\frac{4792,05}{162 / 34}$

$=29,51$ ton $/$ ha

\section{Pemasaran}

Dari hasil penelitian pemasaran jeruk manis yang dilakukan di Kecamatan Pasaman Kabupaten Pasaman Barat dari petani produsen hingga sampai ke konsumen dalam bentuk segar. Jumlah responden lembaga pemasaran dalam penelitian ini adalah 45 responden pemasaran. Lembaga tersebut terdiri dari dua metode yaitu langsung dan tidak langsung ,30 responden dari toke(langsung) dan 15 menjual langsung dari hasil panen (tidak langsung). Responden pemasaran jeruk manis ini dapat dilihat dari beberapa karakteristik antara lain usia, jenis kelamin, pendidikan, dan pengalaman bertani jeruk manis. Karakteristik pemasaran jeruk manis berdasarkan usia kurang dari 35 tahun hingga usia lebih dari 50 tahun. Responden dengan usia kurang dari 35 tahun memasarkan jeruk manis $25 \%$ sedangkan yang lebih dari 50 tahun memiliki persentase sama dengan yang berumur dengan persentase $75 \%$ persen dari total responden penelitian ini.

Berdasarkan data yang diperoleh dilapangan lahan jeruk manis di Kecamatan Pasaman menggunakan sistem langsung dan tidak langsung di karenakan ada yang datang langsung ke lokasi ada yang di antar langsung ke toke, untuk lebih jelasnya dapat dilihat pada tabel dibwah ini:

\begin{tabular}{|c|c|c|c|}
\hline $\mathrm{N}$ & Sistem & & \\
\hline $\mathrm{O}$ & Pemasaran & $\mathrm{F}$ & $\%$ \\
\hline \multirow[b]{2}{*}{1} & Pemasaran & & \\
\hline & langsung & 5 & 11,11 \\
\hline \multirow[b]{2}{*}{2} & Pemasaran & 4 & \\
\hline & tidak langsung & 0 & 88,88 \\
\hline & & 4 & \\
\hline & Jumlah & 5 & 100 \\
\hline
\end{tabular}

\section{5 . Kesimpulan dan Saran}

\section{KESIMPULAN}

Berdasarkan penelitian yang di lakukan tentang Persebaran Komoditi Jeruk Manis Kecamatan Pasaman Kabupaten Pasaman Barat dapat di simpulkan sebagai berikut:

a, Pola persebaran jeruk manis di Kecamatan Pasaman Kabupaten Pasaman Barat adalah disperset (Tersebar )

b. Tingkat Produkifitas tanaman jeruk manis di Kecamatan Pasaman Kabupaten Pasaman Barat 4,9 ton/th

c. Sstem pemasaran jeruk manis di Kecamatan Pasaman Kabupaten Pasaman Barat adalah tidak langsung atau melalui toke

\section{DAFTAR PUSTAKA}

Anonim.2011JerukManis 
http://,wikipedia,org/wiki/jeru

k-manis.(diakses pada

tanggal, 18 Desember 2014)

Badan Pusat Statistik Pasaman

BaratTahun 2017

Odum, 1971. Dasar-Dasar Ekologi.

Edisi ketiga Gadjah Mada

University Press. Yogyakarta

Rahardi F, 2004. Mengurai Benang

Kusut Agribisnis Buah

Indonesia. Penebar Swadaya :

Jakarta

Rani, 2003, pola sebaran spasial suatu

spesies berbagai macam

indeks, gramedia pustaka

utama, Surakarta 